\title{
Desafios para o design de informação em ambientes de realidade aumentada
}

\section{Challenges for Information Design in Augmented Reality}

\author{
Romero Tori
}

realidade aumentada, realidade aumentada espacial, hud, etiquetas virtuais

\begin{abstract}
O design de informação é um processo que depende, em grande medida, do suporte de mídia empregado. A transposição de mídia impressa para mídia digital, por exemplo, vem permitindo a exploração de recursos de interatividade, atualização em tempo-real e personalização, entre outros, mas também tem trazido grandes desafios aos designers. A falta de controle sobre formatos, resoluções, fontes, cores e outros aspectos dos dispositivos de exibição digital são apenas algumas das dificuldades dos projetistas de interface, certamente não as únicas, nem as menores. O que se esperar então de uma mídia cujo suporte de exibição seja o próprio ambiente? É o caso da "Realidade Aumentada" (RA), que após vários anos de incubação em laboratórios de pesquisa e eventos científicos especializados, começa a se tornar viável como meio de comunicação e, portanto, como mais uma opção tecnológica a ser considerada pelos designers de informação. A RA é uma evolução da conhecida "Realidade Virtual" (RV), com a diferença de que, em lugar de se buscar a imersão do usuário em um ambiente virtual, se enriquece o ambiente real com informações virtuais a esse integradas. A partir da experiência do autor em diversos projetos de pesquisa envolvendo a tecnologia de realidade aumentada, este artigo faz uma síntese dos conceitos fundamentais envolvidos e discute alguns dos desafios que devem ser enfrentados pelos designers de informação que decidirem utilizá-la.
\end{abstract}

augmented reality, spatial augmented reality, hud, virtual labels

Information design is a process that depends largely on the employed media support. The translation of printed media to digital media, for example, is allowing the exploitation of resources, interactivity, real-time update and personalization, among other benefits, but also has brought great challenges to designers. The lack of control over formats, resolutions, character fonts, colour and other aspects of digital display devices are just some of the difficulties faced by interface designers, and certainly not the only ones, nor the smallest. What then can one expect of a media that uses the very environment as its display support? This is the case of "Augmented Reality" (AR), which after several years of incubation in research labs and specialized scientific events, is beginning to become viable as a communication medium and, therefore, as another technology alternative to be considered by information designers. AR is an evolution of the well known "Virtual Reality" (VR), with the difference that, instead of seeking immersion of the user in a virtual environment, it enriches the real environment with virtual information. From the author's experience in various research projects involving augmented reality technologies, this article makes a summary of key concepts involved and discusses some of the challenges that must be faced by information designers willing to use them.

\section{Introdução}

Finalmente, após longo período de maturação nos laboratórios de pesquisa, a realidade aumentada (RA) começa a despontar como um novo meio de comunicação à disposição dos designers de informação. O enorme potencial dessa nova mídia ainda é pouco explorado, mas formas criativas de visualização de informação virtual sobreposta ao ambiente real vêm surgindo com freqüência crescente. Alguns exemplos podem ser destacados: volante impresso em anúncio que permite controlar a direção de um automóvel virtual disponível no site do fabricante; jogos que permitem a interação com criaturas virtuais tridimensionais flutuando sobre cartões manipulados pelos jogadores ou diretamente com o próprio corpo (Bernardes et. al. 2008); um projetor que exibe informações das estruturas internas das paredes, simulando um raio-X (Miranda et. al. 2008); etiquetas virtuais exibidas sobre objetos e pessoas reais (Peterson 2006); orientações sobre a estrada e o trajeto projetadas à frente do motorista (Liu 2003); orientações durante o processo cirúrgico projetadas sobre o corpo do paciente (Preece et. al. 2005: 2).

Como alerta Mogel (2000:334), novas tecnologias de comunicação capturam a atenção por certo tempo, independentemente da qualidade do conteúdo. Tão logo deixe de ser "novidade", a nova mídia somente será bem aceita se trabalhada de acordo com os fundamentos e as boas práticas da comunicação e do design. Faz-se necessário que o designer tenha pleno domínio 


\section{Infadesıgn}

sobre os recursos oferecidos pela tecnologia e, principalmente, das limitações e requisitos que

a acompanham. Tomemos como exemplo um experiente e bem sucedido designer gráfico. Dificilmente esse profissional será bem sucedido se tentar aplicar métodos e conceitos de mídia impressa, sem as devidas adaptações, em projetos de mídia digital interativa. A Realidade Aumentada, ainda que digital e interativa, possui peculiaridades e limitações bem diferentes das mídias digitais "convencionais". Desafios similares aos enfrentados por profissionais gráficos, que precisaram se adaptar ao dinamismo incontrolável das mídias interativas atuais, aguardam os designers envolvidos com projetos de realidade aumentada. Em lugar de passar do papel para o monitor, esses profissionais precisarão migrar do monitor para o ambiente real, que se torna o "dispositivo de saída" para suas criações virtuais. Dominar as técnicas e conceitos que fundamentam essa nova tecnologia, entender suas limitações e conhecer suas possibilidades, são os desafios com os quais os designers de informação começam a se deparar, e que precisam ser vencidos antes que "realidade aumentada" deixe de ser apenas curiosidade.

A partir da experiência do autor em diversos projetos de pesquisa envolvendo a tecnologia de realidade aumentada, este artigo faz uma síntese dos conceitos fundamentais envolvidos nessa nova mídia e discute alguns dos desafios que devem ser enfrentados pelos designers de informação que decidirem utilizá-la.

\section{Realidade Aumentada}

Técnicas para se iludir os sentidos humanos vêm sendo desenvolvidas e aplicadas há séculos por artistas, engenheiros, cientistas e ilusionistas. Um marco na integração de tecnologia e arte para envolver o público em realidades alteradas é o que Moholy-Nagy (1924) chama de "Teatro da Totalidade", uma experiência da Escola de Bauhaus que deu origem a um novo tipo de teatro integrando tecnologia, arte, atores e público. Na área cinematográfica uma importante contribuição para a tecnologia de imersão foi dada por Morton Heilig (1955) com sua visão do que seria o "cinema do futuro" e seu equipamento denominado "Sensorama". Essa máquina envolvia os principais sentidos humanos, por meio de visores estereoscópicos, altofalantes, odores, vento e vibrações, O Sensorama não chegou a ser um sucesso, talvez por não ter conseguido superar a fase da curiosidade e oferecer conteúdos interessantes, mas foi inspirador para os pesquisadores que desenvolveram o que hoje conhecemos como Realidade Virtual (RV) e Realidade Aumentada (RA).

A realidade aumentada é uma evolução da conhecida tecnologia de realidade virtual. Enquanto a RV tem como objetivo a imersão do usuário em um ambiente virtual, de tal forma que elementos e ocorrências do mundo real precisam ser impedidos de interferir no mundo virtual a fim de que a sensação de imersão do usuário não seja prejudicada, a RA integra as informações virtuais ao ambiente físico. Com a RA em lugar da RV, além de o usuário não mais precisar ser privado das sensações provindas do mundo exterior, e do maior realismo experimentado, não há necessidade de se recriar um mundo a parte, reduzindo-se assim os custos de desenvolvimento e aumentando-se as possibilidades de aplicação. Por outro lado, novos problemas e dificuldades surgem, à medida que elementos virtuais e reais precisam coexistir e interagir de forma consistente.

\section{Caracterização da Realidade Aumentada}

Segundo Azuma (2001) um sistema de realidade aumentada deve necessariamente apresentar três características:

- integrar elementos virtuais, gerados por tecnologia computacional, a um ambiente real (ou integrar elementos reais a ambientes virtuais);

- ser interativo e responder em tempo real; 
- prover registro, em três dimensões, entre elementos reais e virtuais (ou seja, as posições espaciais dos elementos virtuais devem ser bem definida e consistentes com o ambiente real)

Para se identificar sistemas de RA basta uma análise dos requisitos acima. Vejamos um exemplo simples. Dificilmente alguém classificaria um aparelho de televisão exibindo imagens, mesmo que digitais e interativas, como uma aplicação de RA, apesar de esse equipamento produzir informações virtuais misturadas ao ambiente real, uma vez que não é atendido o requisito de registro entre os elementos exibidos na tela e o ambiente ao seu redor. Se, no entanto, for criado um objeto cenográfico em forma de aquário, integrando uma tela de TV na qual é exibido um filme com peixes nadando, esse conjunto poderá ser classificado como uma aplicação de RA. O mesmo raciocínio valeria se embutíssemos a tela de TV numa parede e projetássemos a imagem de uma janela virtual. No entanto, a ilusão do aquário ou da janela seria facilmente quebrada se o usuário se movimentasse e percebesse que as imagens projetadas são bidimensionais. Para melhorar a ilusão seria necessário o rastreamento da posição da cabeça do usuário, mudando-se a projeção exibida de acordo com o seu ponto de vista. Outro problema seria no caso em que elementos virtuais são projetados sobre um objeto real e esse objeto é movido. Para que o registro seja preservado a projeção deverá acompanhar o movimento do objeto. A solução mais uma vez, envolve o uso de técnicas de rastreamento, desta vez dos objetos.

\section{Contínuo Real-Virtual}

Figura 1: Representação do contínuo real-virtual a partir de proposta de Milgram \& Kishino (1994).

Ambiente Real

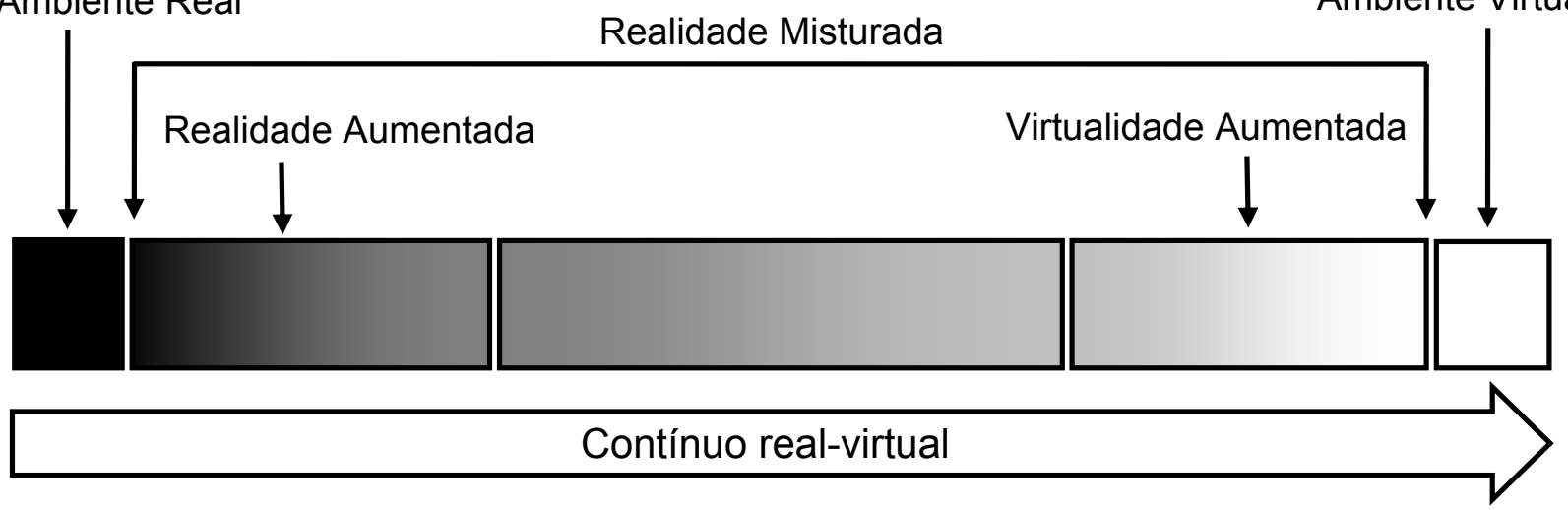

Milgram \& Kishino (1994) definiram o chamado "contínuo real-virtual" (Fig. 1), um espectro que engloba e ordena todo tipo de instalação interativa, em função da proporção entre virtual e real existente no ambiente. Na extremidade esquerda do espectro situam-se aquelas aplicações que não se utilizam de recursos virtuais e na extremidade oposta são alocados os ambientes totalmente virtuais, ou seja, os sistemas imersivos de realidade virtual. Entre esses dois extremos são dispostos todos os demais ambientes que misturam elementos virtuais e reais. Na primeira faixa desse miolo estão aqueles sistemas denominados de Realidade Aumentada, os quais propiciam a inserção de elementos virtuais em ambientes reais, com alta predominância destes últimos. Um exemplo é o sistema AR-XRAY (Miranda et. al. 2008), mostrado na Fig. 2, que possibilita a visualização virtual de informações de estruturas internas de edificações. Na última faixa temos os sistemas de Virtualidade Aumentada, que se caracterizam pela inserção de elementos virtuais em mundos virtuais, como por exemplo, um video-avatar (video tridimensional de uma pessoa em tempo-real) inserido em ambiente virtual e com possibilidade de interação com os objetos e personagens virtuais. No centro desse espectro restam as aplicações, classificadas como realidade misturada, que mesclam virtual e real sem clara predominância de um ou outro.

O contínuo real-virtual é uma referência importante para análises e discussões teóricoconceituais. Na prática, contudo, a classificação de virtualidade aumentada é pouco empregada e os sistemas que mesclam real e virtual, em qualquer proporção, costumam ser referidos 


\section{InfDdesıgn}

simplesmente por "realidade aumentada" ou, como preferem alguns autores, por "realidade misturada".

Figura 2: Representação artística do funcionamento do sistema AR X-RAY. (Miranda et. al. 2008)
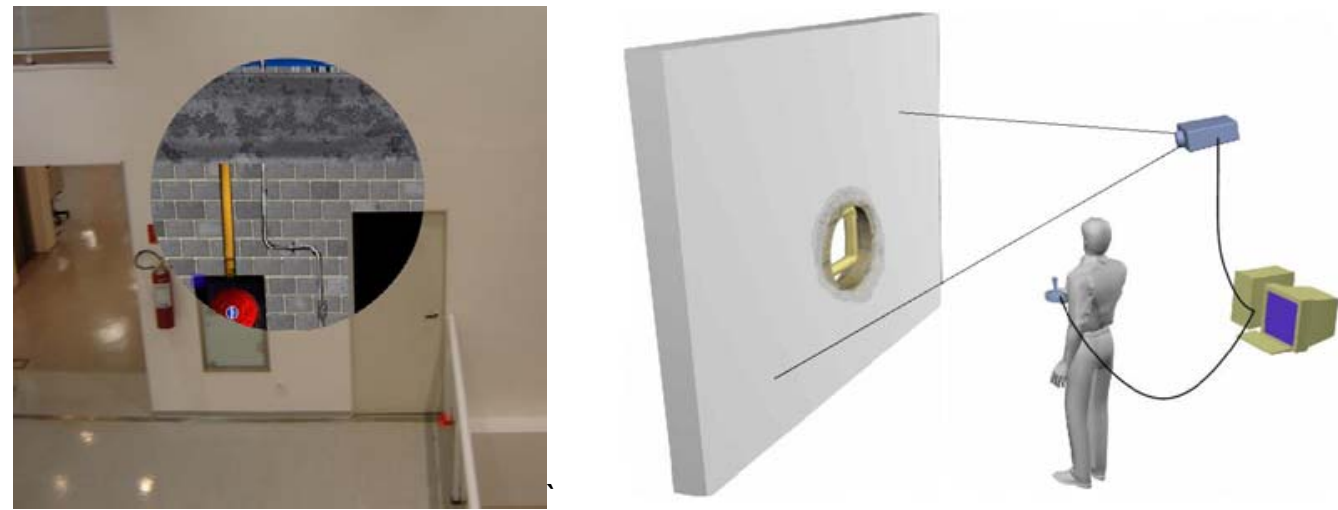

\section{Técnicas de Realidade Aumentada}

Há inúmeras formas de se misturar elementos virtuais e reais, incluindo-se todos os sentidos humanos. A seguir são apresentadas as técnicas mais comuns, com foco em visualização.

- video see-through: por meio de óculos ou capacetes de realidade virtual, que isolam a visão externa do usuário e exibem imagens virtuais tridimensionais (estereoscópicas), e uma câmera acoplada à cabeça do usuário (ou par, quando se deseja efeito estereoscópico), a cena real é captada, elementos virtuais são sobrepostos digitalmente e a cena editada é enviada ao usuário, que tem a sensação de estar vendo o mundo real enriquecido com informações digitais; essa técnica permite ao usuário caminhar normalmente pelo ambiente, mas havendo falhas no dispositivo de exibição, na precisão e qualidade da imagem, ou na captação da imagem, o usuário poderá perder a correta visualização do ambiente;

- optical see-through: nesta técnica utiliza-se um dispositivo óptico semi-transparente, em geral um par de óculos, que gera imagens virtuais ao mesmo tempo que permite a visualização do ambiente real sobre o qual as informações digitais são sobrepostas; uma qualidade importante dessa técnica é possibilitar a visão direta do ambiente, sem intermediação tecnológica, garantindo maior segurança no caso de falha no dispositivo; outra característica é a maior sensação de presença no espaço real; há, contudo, diversas dificuldades técnicas nessa solução, com destaque para: registro entre virtual e real, não eliminação da visão de objetos que deveriam ser ocultados pelos objetos virtuais, grande discrepância entre qualidade de imagens reais e virtuais;

- visualização indireta: neste caso a sobreposição entre informações virtuais e ambiente real é visualizada em um monitor ou numa tela de projeção; a tecnologia utilizada para a mesclagem é a mesma do video see-through; em algumas situações a tela pode simular um "espelho mágico", através do qual o usuário se observa e ao ambiente a seu redor, bem como os elementos virtuais adicionados digitalmente; um projeto pioneiro que se utilizou desse recurso é o sistema ALIVE (Maes et. al. 1997), no qual uma pessoa, visualizando-se no ambiente real, interage com um cão virtual inserido à cena real projetada à sua frente; esta é a solução mais largamente utilizada, devido a seu baixo custo, bastando uma webcam para se ter a possibilidade de experimentar a tecnologia de RA; a biblioteca gratuita e aberta AR Toolkit ${ }^{1}$ é um entre diversos recursos disponíveis aos interessados em desenvolver aplicações de RA de baixo custo; um exemplo de produto desenvolvido com essa tecnologia é o "Mixed

\footnotetext{
${ }^{1}$ http://www.hitl.washington.edu/artoolkit/
} 
Reality Book" ( Grasset et. al. 2008), um livro real, que ao ser folheado é enriquecido com informações virtuais que podem ser visualizadas por video see-through ou, indiretamente, em um monitor;

- RA Espacial (RAE): na realidade aumentada espacial (Bimber \& Raskar 2005) o enriquecimento virtual do ambiente é obtido por meio de projeções diretamente sobre objetos do ambiente real; o AR X-RAY (Miranda et. al. 2008) é um exemplo de aplicação de RAE; um projeto pioneiro nessa área é o sistema Shader Lamps (Raskar et. al. 2001) que possibilita que texturas virtuais e informações sejam "pintadas" sobre superfícies dos objetos; a grande vantagem da RAE é dispensar o uso de capacetes, óculos ou outro dispositivo acoplado ao corpo e a visualização direta das informações virtuais no ambiente real.

\section{Desafios para o design da informação em ambientes de RA}

Preece et. al. (2005:58) destacam a importância de se conhecer bem o espaço do problema e de se evitar a tentação de rapidamente se partir para o design da interface física. Mijksenaar (1997: 12) apresenta o exemplo de uma encomenda para redesenho das instruções de abertura da porta de um determinado modelo de avião que foi respondida pelos designers com uma sugestão de redesenho do fecho da porta (o problema não era de design da informação, mas de design de produto). Löwgren \& Stolterman (2004: 3) afirmam que "conhecer um material significa conhecer também suas desvantagens". Esses mesmos autores ressaltam ainda que "o design se torna mais complexo quando se combinam diferentes materiais com qualidades específicas" e que "a dificuldade é muito grande quando o material é uma composição de artefatos técnicos e sistemas sociais". Realidade aumentada é uma tecnologia que exige uma combinação precisa, harmoniosa e complexa de materiais físicos, digitais e humanos, elevando-se assim a ordem de grandeza dos conhecimentos envolvidos e das dificuldades a ser enfrentadas.

Ao se fazer o design de determinado sistema muito cuidado deve ser tomado para não se misturar requisitos do problema com requisitos das possíveis tecnologias a serem empregadas em sua solução. Os primeiros são restrições do problema, que em tese não podem ser modificadas, a menos que se altere o próprio objetivo em questão. Já os requisitos tecnológicos podem ser equivocadamente tomados como imperativos, juntando-se às chamadas "restrições fictícias" (geradas por uma especificação mal feita do problema), sendo que poderiam ser eliminados simplesmente pela substituição da tecnologia escolhida (certamente a nova tecnologia trará novos requisitos que também deverão ser avaliados). A falta de cuidado em se isolar o que é problema do que é decisão de projeto tem gerado muitos produtos e serviços desnecessariamente complexos ou caros, o que motivou a injusta frase de autor desconhecido: "A tecnologia veio para resolver problemas que antes dela não existiam". Seria mais ou menos como se o parlamento de determinado país fictício gastasse a maior parte de seus recursos humanos e materiais em comissões e discussões visando investigar e resolver escândalos e problemas gerados pelos próprios parlamentares.

Portanto, o primeiro desafio para o design da informação em ambientes de RA é o de, após estudo aprofundado sobre o problema, o público-alvo e cenário, decidir se realidade

aumentada seria efetivamente a melhor solução para a interface de comunicação e interação com a informação. Após decisão inicial pela tecnologia de RA recomenda-se o checklist a seguir, antes do referendo definitivo:

- O projeto se sustentaria após eliminados os fatores "novidade"e "deslumbramento"?

- O sistema demandaria ajustes e calibrações constantes? Se o uso se der em espaço público, quais os recursos necessários e custos para se manter o sistema calibrado e operando adequadamente? Se o uso for caseiro, o usuário teria paciência e motivação para ajustes frequentes?

- Que condições especiais de iluminação, acesso, isolamento e segurança seriam demandadas? 


\section{Infodesıgn}

- Quais seriam os requisitos tecnológicos (sistemas operacionais, hardware etc..) e quais as possibilidades de que atualizações tecnológicas demandem atualizações no sistema?

- Considerando-se a forma de distribuição e uso do sistema, assim como o perfil do público-alvo, quais seriam os impactos dos requisitos de manutenção, calibração e atualização do sistema?

- Se o sistema for de uso público e demandar uso de dispositivos acoplados ao corpo como deverão ser tratados os aspectos de segurança e higiene? Quais os impactos no fluxo dos usuários? Poderá haver formação de filas, descontentamentos ou frustrações?

- Os custos (em tempo, atenção, esforço e, eventualmente, em dinheiro) que deverão ser assumidos pelo usuário seriam compensados pelos benefícios por ele percebidos?

Ultrapassado o primeiro desafio, e tendo decidido pela tecnologia de RA, o designer se defrontará com diversos outros problemas (sem, claro, se considerar aqueles relacionados diretamente à implementação do sistema, tarefa essa a cargo de profissionais de engenharia e/ou computação). Reunimos alguns dos mais comuns, relacionados a diversos tipos de aplicação, que serão discutidos a seguir: registro, rastreamento e movimentação, óptica e iluminação, HUD, densidade de dados, fatores humanos, realismo, etiquetagem virtual, limitações técnicas.

\section{Registro}

A perfeita justaposição entre elementos virtuais e reais, garantindo-se a continuidade, em tempo-real, entre os mesmos, é fundamental em ambientes de realidade virtual. Como alerta Ware (2000:42) "a posição do ponto de vista do observador deve ser perfeitamente conhecida e as posições dos objetos, formas e ambiente local precisam estar armazenadas no computador" e "dificuldades de se obter registro correto bem como portabilidade do sistema não devem ser subestimados". Em aplicações envolvendo visualização de informação há ainda a ser considerado o relacionamento espacial entre dados e objetos.

Registro demanda calibração, o que pode se tornar o ponto fraco do sistema, seja pelo incômodo que pode causar ao usuário, pela dificuldade técnica, pelo impacto na usabilidade do sistema, por dependência de usuário e/ou ponto-de-vista, ou por perda de calibração durante o uso, entre outros problemas. Sistemas indoor em geral são mais robustos quanto ao registro, uma vez que permitem a calibragem prévia de todo o ambiente e equipamentos. Sistemas outdoor e baseados em dispositivos móveis, uma tendência crescente, são os que apresentam maiores dificuldades técnicas para calibração e registro.

\section{Rastreamento e movimentação}

O rastreamento não deve ser confundido com registro, apesar de o primeiro ser fundamental para que o segundo seja obtido. Rastrear significa saber a posição exata, no espaço, de objetos e/ou partes do corpo do usuário. Pelo rastreamento da cabeça do usuário, ou dos olhos para uma melhor precisão, é possível se determinar o ponto-de-vista e assim calcular perspectivas, projeções, iluminações e oclusões. Pelo rastreamento de objetos da cena esta pode ser atualizada em tempo real, permitindo assim que haja movimentação de elementos do mundo real e que o registro seja mantido. $O$ rastreamento torna-se mais complexo quando se deseja permitir mobilidade do usuário e, mais ainda, quando o sistema é outdoor. Há diversas técnicas para rastreamento, sendo os sensores eletromagnéticos os mais precisos, e também os mais dispendiosos. Com a evolução dos processadores gráficos e barateamento das câmeras de vídeo há uma tendência de se usar rastreamento óptico. Como câmeras são praticamente acessórios padrão em celulares, essa deve ser a solução preferida em aplicações móveis.

Uma técnica simples, barata e, consequentemente muito difundida, é a realização de rastreamento por meio de câmeras e marcadores fiduciais (Fig. 3). O marcador fiducial é uma imagem plana, em geral contornada por uma borda retangular, cuja imagem captada por uma 
câmera é analisada de tal forma a se obter, em função da deformação de perspectiva sofrida, a posição do mesmo no espaço tridimensional, bem como sua orientação em relação à câmera. De posse dessa informação fica fácil para o sistema inserir uma imagem tridimensional virtual na imagem real, aplicando-se as mesmas transformações geométricas do marcador. Uma das aplicações mais conhecidas é o de possibilitar ao usuário que manipule um objeto virtual segurando um cartão exibido para uma câmera. Mas há muitas outras possibilidades, como, por exemplo, a visualização de informações sobre um objeto apontando-lhe um dispositivo móvel com câmera ou o acoplamento de marcadores em pontos do corpo do usuário para rastreá-lo.

Figura 3: Uso de marcador fiducial para rastreamento em aplicações de RA.
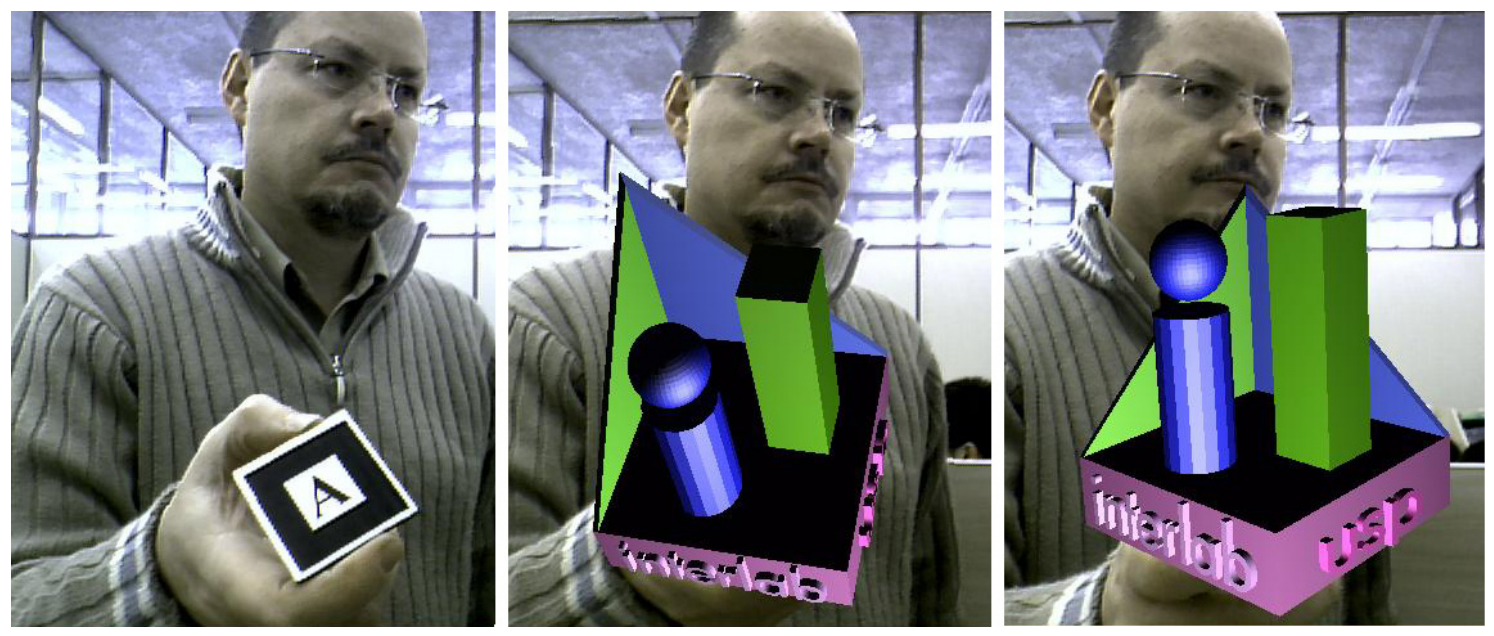

\section{Óptica e iluminação}

Atenção especial deve ser dada a questões de óptica e de iluminação em sistemas de RA. Além dos problemas de registro e rastreamento, já abordados, há muitos outros detalhes que podem influir na qualidade e desempenho do sistema. O sistema óptico humano é extremamente complexo e sensível. Fatores como foco, orientação do globo ocular, sombras e perspectiva são utilizados pelo cérebro para resolver a difícil equação (matematicamente impossível, diga-se, posto não haver uma única solução) de se extrair informações tridimensionais de imagens bidimensionais. A sobreposição de texturas virtuais sobre cenas reais pode levar a indesejáveis camuflagens, que como bem define Pettersson (2002: 112) equivalem a se fazer "design de desinformação".

Dependendo da aplicação, falhas na interpretação do cérebro podem causar problemas de segurança. Ware (2000: 42) cita como exemplo evidências de que a apresentação de informações projetadas sobre o parabrisa da aeronave, sobrepostas à visão que o piloto tem do mundo real, pode interferir na percepção de distância de objetos reais. Isso porque o cérebro se utiliza da informação de foco para estimar distâncias e essa informação é alterada quando o piloto lê as informações projetadas. O mesmo autor levanta uma série de problemas ópticos e de percepção que podem ocorrer em dispositivos de realidade virtual e aumentada, como os HMDs (Head-mounted displays).

\section{HUD}

HUD (Head-up Display) é uma técnica utilizada na aviação desde 1960 (Liu, 2003) para reduzir a necessidade de pilotos desviarem a atenção do ambiente exterior para observação do painel de instrumentos, ou seja, uma forma de exibição de informação a frente do campo de visão do piloto, mantendo-o, assim com a cabeça erguida ("head-up"). A técnica é bastante simples e se baseia no fato de que o parabrisa não é $100 \%$ transparente, sendo possível projetar informações sobre o mesmo, as quais serão vistas pelo piloto como sobrepostas ao mundo real. A simples exibição de informações virtuais misturadas ao cenário real, no entanto, não se 


\section{Inf0desıgn}

configura como uma aplicação de RA. Para que isso ocorra é necessário que as informações projetadas tenham registro com objetos do mundo real, o que torna a solução bastante complexa, por envolver sistemas ópticos diferentes e desacoplados. HUDs vem sendo aplicados com sucesso em automóveis (Liu 2003) (Conceição 2008), mas ainda com pouca exploração de recursos de registro e rastreamento, sendo um promissor campo de estudos para designers da informação.

\section{Densidade de dados}

Ao se sobrepor o mundo real com um grande volume de dados virtuais a visualização pode se tornar confusa e ilegível (Azuma 2001: 39). Diferentemente de aplicações convencionais de visualização de informação, que possuem toda a área de exibição sob controle, em aplicações de RA não há como se alterar o cenário do mundo real, aumentando-se o desafio para o designer da informação. Ao realizar filtragens dos dados a serem exibidos é preciso classificar os elementos reais para que se possam priorizar as informações a serem exibidas, ou de alguma forma destacadas, a cada momento.

Em aplicações que visam oferecer ao usuário algum tipo de visualização interna ou através de objetos, como o sistema AR X-RAY (Miranda 2008), o problema que surge é o chamado "paradoxo da visão de raio-x do Super-Homem" (Hinckley et. al. 1994). Nesse caso o designer é confrontado entre a opção de exibir muita informação sobre as estruturas internas, com o risco de confundir o usuário, e o de exibir apenas um nível de informação, prejudicando o efeito "raio-X" e privando o usuário de importantes referências visuais de orientação e profundidade.

A melhor solução para a alta densidade de informações que pode ocorrer em ambientes de RA nem sempre deve ser a simplificação ou redução dos dados. Edward Tufte (1990: 51) questiona essa abordagem afirmando que "desordem e confusão são falhas do design, não atributos da informação" e que menos detalhes podem tornar a informação mais ambígua e desinteressante. Uma forma de se lidar com a complexidade de informação é a criação de níveis e separações (Tufte 1990: 52). A dificuldade no caso da RA, como mencionado no início desta seção, é a manipulação do cenário real sobre o qual as informações são sobrepostas.

\section{Fatores Humanos}

Azuma (2001: 40) relaciona os fatores mais significativos relacionados aos efeitos no ser humano do uso prolongado de sistemas de realidade aumentada, a seguir apresentados.

- Latência: o atraso na atualização das imagens pode causar a percepção de que há erros de registro no sistema, comprometendo o realismo e afetando o desempenho do usuário; em alguns casos pode provocar desconforto e até mal estar;

- Percepção de profundidade: falhas na percepção de profundidade também causam sensação de erros de registro; a estereoscopia (Tori et. al. 2006) contribui para uma melhor percepção de profundidade, mas as técnicas hoje utilizadas para produzir esse efeito trazem outros problemas, como foco, conflitos entre convergência e acomodação da visão; um outro aspecto, a correta oclusão de objetos, é essencial para a percepção de profundidade;

- Adaptação: o ser humano consegue facilmente se adaptar a informações mediadas por tecnologia, mas durante o processo de adaptação o desempenho pode ser bastante comprometido; um exemplo é a adaptação ao deslocamento do ponto de vista provocado por sistemas do tipo video see-through em que a câmera é colocada acima da cabeça do usuário, que requer adaptação para sua utilização como também após sua retirada, para retorno ao uso normal da visão;

- Fadiga e esforço visual: equipamentos de RA acoplados ao sistema visual não são adequados ao uso prolongado, podendo causar fadiga e desconforto; os sistemas de realidade aumentada espacial e de exibição indireta, por dispensarem tais equipamentos permitem maior tempo de uso;

\section{Realismo}

A maioria das aplicações de RA procura reproduzir as informações virtuais com o máximo de realismo possível para uma melhor integração com os elementos reais da cena. Para tanto não 
basta a qualidade e resolução do processo de renderização. Diversos outros fatores precisam ser levados em consideração, tais como: a iluminação dos objetos virtuais, que deve ser compatível com a da cena real; sombras consistentes; compatibilidade de proporções e pontos de vista ; movimentação realista (uma pessoa que parece flutuar em vez de andar na cena quebra o realismo mesmo que tenha sido renderizada com extrema qualidade).

Outra abordagem, ainda pouco explorada, é a proposta por Fischer et. al. (2006), que em vez de buscar maximizar o realismo dos objetos virtuais, reduz o realismo da cena real, tornando assim mais difícil a distinção visual entre elementos virtuais e reais. Para obter tal efeito os autores passam cena real e objetos virtuais por filtros que transformam as imagens em desenhos animados (cartoons).

\section{Etiquetagem Virtual}

Uma aplicação bastante comum em sistemas de informação baseados em RA é a colocação de etiquetas virtuais (labels) com dados sobre os objetos reais da cena. As possibilidades de aplicação são muitas, tais como a visualização de informações a respeito de obras expostas em um museu, consulta de características de materiais utilizados na construção de edifícios, crachás virtuais conectados a pessoas reais, instruções sobre montagem de equipamentos ou mobiliário, informações sobre poderes e habilidades de personagens em jogos de RPG etc. A "etiquetagem virtual" é tão útil quanto desafiadora para os designers de informação. Alguns dos problemas que surgem são: legibilidade, oclusão (por outras etiquetas ou por outros objetos), relacionamento espacial entre etiquetas e objetos, desordem e confusão (cluttering) causadas pelo excesso de etiquetas na cena, posicionamento das etiquetas em relação aos objetos e ao ponto de vista, tipologia adotada, formas de destaque e contraste, e compatibilização entre o estilo da etiqueta com a cena renderizada.

Para solucionar o típico problema de separação de etiquetas em cena para se evitar oclusões que comprometam a legibilidade algumas técnicas vem sendo desenvolvidas. Peterson et. al. (2009) fez um estudo que comparou duas técnicas comuns de separação das etiquetas no plano de visualização $2 \mathrm{D}$ com uma terceira que usa estereoscopia e trabalha também com a profundidade da cena. Após análise de desempenho de voluntários desempenhando uma determinada tarefa em sistemas de RA que utilizavam os três métodos mencionados, os autores notaram ganho significativo em comparação com a condição de controle (sem aplicação de técnicas de separação) no tempo de resposta do sistema que utilizava separação por profundidade e estereoscopia.

A etiquetagem virtual é uma poderosa técnica para visualização de informação e interação em ambientes de realidade virtual, mas que ainda demanda muita pesquisa e aprimoramentos.

\section{Limitações técnicas}

Ainda não existe uma técnica ideal para a geração de informações virtuais sobrepostas ao ambiente real. Enquanto não se chega, ao menos proximamente, ao que Ivan Sutherland (1965) divisou como sendo o "ultimate display", um sistema de projeção tão perfeito que criaria objetos virtuais indistinguíveis dos reais, é muito importante selecionar a tecnologia mais adequada a cada situação. Para tanto é necessário que se conheçam as qualidades, defeitos e limitações das diversas técnicas hoje utilizadas em realidade aumentada. Apresentamos a seguir uma síntese das principais.

- optical see-through: vantagens: não elimina a visão direta do ambiente real; em geral mais leve e menos volumoso que os capacetes utilizados em técnicas de optical-seethrough; desvantagens: campo de visão limitado; pouco brilho e contraste, dificultando uma integração visual adequada dos elementos virtuais com o ambiente real; dificuldade para oclusão de objetos reais pelos virtuais; dificuldade de registro entre

elementos reais e virtuais;

- video see-through: vantagens: permite oclusão dos objetos reais pelos virtuais; facilita a equalização de brilho, contraste, iluminação e resolução entre imagens reais e virtuais; facilita o registro entre elementos reais e virtuais; desvantagens: erros de paralaxe (devido a diferenças entre câmeras e olhos do usuário quanto a posição e 


\section{Infadesıg}

determinados parâmetros ópticos); campo de visão limitado; não possibilita a visão direta do ambiente (em caso de falha na câmera ou nos óculos o usuário fica cegado);

- visualização indireta: vantagens: além de possuir as mesmas vantagens de video see-through tem baixo custo (só precisa de uma webcam e um monitor comum) e dispensa acoplagem de dispositivos ao corpo; desvantagens: não possibilita visão direta do ambiente; campo de visão limitado; mobilidade limitada;

- RA Espacial (RAE): vantagens: dispensa acoplagem de dispositivos ao corpo; não elimina a visão direta do ambiente real; não limita o campo de visão; possibilita mobilidade; desvantagens: os objetos da cena que receberão projeção precisam ser previamente modelados; a iluminação ambiente interfere nas projeções; as cores e texturas das superfícies interferem nas projeções; projetores ainda são equipamentos caros; projetores portáteis possuem baixa luminosidade.

\section{Conclusões}

A tecnologia de realidade aumentada (RA), que possibilita a extensão do ambiente real e seu enriquecimento com elementos virtuais interativos, harmoniosa e precisamente integrados aos elementos reais, é hoje uma alternativa viável e atraente para a exibição de - e interação com informação. Os designers de informação passam a ter mais uma opção para seus projetos, opção essa que deve apresentar relação custo-benefício cada vez mais vantajosa, à medida que custo e qualidade da tecnologia avancem em sentidos opostos, que mais pessoas tenham acesso à tecnologia, e que a cultura de sua utilização floresça. No entanto, as complexidades de materiais e de técnicas envolvidos devem ser bem dominadas pelo designer de informação, assim como as limitações e requisitos que apresentam. Cuidado especial deve ser tomado para que a decisão por se empregar uma solução baseada em tecnologia de RA não seja tomada de forma precipitada e sem cotejamento com outras possíveis soluções. Visando-se facilitar a apropriação desse novo repertório de opções tecnológicas e auxiliar o designer no processo de desenvolvimento de aplicações baseadas em realidade aumentada, este artigo apresentou e discutiu os principais conceitos e desafios envolvidos.

\section{Agradecimentos}

O autor agradece aos professores Fábio Roberto de Miranda, Claudio Eduardo Saunorins Bueno e Eduardo Costa Jacober, companheiros de pesquisa em realidade aumentada no Laboratório de Pesquisa em Ambientes Virtuais (LPAI) do Centro Universitário Senac, à diretoria de pós-graduação e pesquisa do Centro Universitário Senac, pelo financiamento à pesquisa da qual este artigo se originou, e aos colegas e alunos do Mestrado em Design e do curso de Bacharelado em Design de Interfaces do Centro Universitário Senac, pelas ricas discussões e interações das quais me proporcionaram participar. $O$ autor também agradece aos colegas do Interlab (Laboratório de Tecnologias Interativas) da Escola Politécnica da USP que colaboraram com essa pesquisa, em especial ao Professor Ricardo Nakamura e aos pesquisadores João Luiz Bernardes Jr, Daniel Makoto Tokunaga, Alexandre Tomoyose, Silvio Sanches, Valdinei Freire da Silva, Lucas Trias, e aos alunos do curso de Design da USP Carina Missae, Pedro Câmara, Bruno Santos Viana e Samuel Cruz. 


\section{Referências}

Azuma, R.; Baillot, Y.; Behringer, R.; Feiner, S.; Julier, S. \& Macintyre, B. 2001. Recent Advances in Augmented Reality. IEEE Computer Graphics and Applications, vol. 21, no. 6, pp. 34-47.

Bernardes Jr, J. L., Tori, R., Nakamura, R., Calife, D., Tomoyose, A. 2008. Augmented Reality Games In: Extending Experiences: Structure, analysis and design of computer game player experience. Lapland : Lapland University Press, p. 228-246.

Bimber, O. \& Raskar, R. 2005.Spatial Augmented Reality. A. K. Peters. 372p.

Biocca, F.; Levy, M. R. 1995. Communication in the Age of Virtual Reality. Lawrence Erlbaum Associates. Hillsdale, NJ.

Conceição, M. G. 2008. CO-PILOT: Dispositivo Visual de Auxílio ao Motorista. Monografia de conclusão de Curso. São Paulo: Centro Universitário Senac. 52 pp.

Fischer, J.; Bartz, D. \& Straßer, W. 2006. The Augmented Painting. In: ACM SIGGRAPH Emerging Technologies Program. Boston, 2006.

Grasset, R.; Billinghurst, M.; Dünser, A. \& Seichter, H. 2007. The Mixed Reality Book: A New Multimedia Reading Experience. In: Proceedings of CHI 2007. New York: ACM. Pp. 1953 1957.

Heilig, M. 1955.The cinema of the future. In: Packer, R; Jordan, K. (ed.). 2001. Multimedia: From Wagner to Virtual Reality. W. W. Norton \& Company, pp. 219-231.

Hinckley, K., Pausch, R., Goble, J. \& Kassell, N. 1994. Passive Real-World Interface Props for Neurosurgical Visualization. Proceedings of the ACM CHI '94 (Conference on Human Factors in Computing Systems), pp. 452-458.

Liu, Y. C. 2003. Effects of using head-up display in automobile context on attention demand and driving performance. In: Displays 24. Elsevier. pp. 157-165.

Löwgren, J. \& Stolterman, E. 2004. Thoughtful interaction design: a design perspective on information technology. Cambridge: MIT Press. 198 p.

Maes, P.; Darrell, T.; Blumberg, B. \& Pentland, A. 1997. The ALIVE system: wireless, full-body interaction with autonomous agents. In: Multimedia Systems, , vol. 5, n. 2. New York: Springer-Verlag, pp. 105-112.

Mijksenaar , P. 1997. Visual Function: An Introduction to Information Design. 010 Publishers. 56 pp.

Milgram, P.; Kishino, F. 1994. A Taxonomy of Mixed Reality Visual Displays. IEICE Trans. Information Systems, vol. E77-D, no. 12, pp.1321-1329.

Miranda, F. R., Tori, R., Bueno, C. E. S, Trias, L. P. 2008. AR X-Ray : portable projector-based augmented exploration of buildings. In: X Symposium on Virtual and Augmented Reality SVR 2008, 2008, João Pessoa. Proceedings of X Symposium on Virtual and Augmented Reality. Porto Alegre: Sociedade Brasileira de Computação, pp.185-195.

Mogel, L. 2000. Careers in communications and entertainment. New York: Kaplan Books. 374 p.

Moholy-Nagy, L. 1924. "Theater, circus, variety," Theater of the Bauhaus. In: Packer, R; Jordan, K. (ed.). 2001. Multimedia: From Wagner to Virtual Reality. W. W. Norton \& Company, pp 1626.

Peterson, S. D.; Axholt, M.; Cooper, M. \& Ellis, S. R. 2009. Visual Clutter Management in Augmented Reality: Effects of Three Label Separation Methods on Spatial Judgments. In: Proceedings of the IEEE Symposium on 3D User Interfaces 2009, Lafayette (LA), USA, pp. $111-118$

Pettersson, R. 2002. Information design: an introduction. John Benjamins Publishing Company. $296 \mathrm{pp}$. 


\section{Infodesıgn}

Preece, J.; Rogers, Y.; Sharp, H. Design de Interação. Porto Alegre: Bookman. 550 p.

Raskar, R.; Welch, G.; Low, K. 2001. Shader Lamps: Animating Real Objects with Image-Based Illumination. 12th Eurographics Workshop on Rendering (EGWR) London.

Sutherland, I. 1965. The Ultimate Display.[1965] In: PACKER, R; JORDAN, K. (ed.). Multimedia: From Wagner to Virtual Reality. W. W. Norton \& Company. 396p. 2001

Tori, R.; Kirner, C. \& Siscoutto, R. (organizadores). 2006. Fundamentos e Tecnologia de Realidade Virtual e Aumentada. Porto Alegre: Sociedade Brasileira de Computação, 2006. 422p. disponível em http://www.interlab.pcs.poli.usp.br; acesso em 15 de abril de 2009.

Tufte, E. 1990. Envisioning Information. Cheshire, Connecticut: Graphics Press; 128 p.

Ware, C. 2000. Information Visualization: Perception for Design. San Francisco, CA: Morgan Kaufmann; 438 pp.

\section{Sobre o autor}

Romero Tori é engenheiro, doutor e livre-docente pela USP. Atualmente é professor titular do Centro Universitário Senac de São Paulo e Professor Associado da Escola Politécnica da USP. Coordena o Interlab Interactive Technologies Laboratory da POLI/PCS-USP. É professor permanente do Mestrado em Design do Centro Universitário Senac e é credenciado, desde 1995, no programa de pós-graduação em Engenharia Elétrica da POLIUSP, sub-área de sistemas digitais (Mestrado e Doutorado, nivel 6 da CAPES). Ministra disciplinas nos cursos de graduação em Design (FAU-USP), Design de Interfaces (Centro Universitário Senac) e Engenharia de Computação (POLI-USP). No Senac coordena o programa PIBIC de iniciação científica e desenvolve pesquisas de design em realidade aumentada. Foi presidente da Comissão Especial de Realidade Virtual da Sociedade Brasileira de Computação SBC (2007-2008), é membro do Conselho Deliberativo da Escola do Futuro da USP, desde sua fundação em 1993, e membro do Conselho de Ensino Pesquisa e Extensão (CONSEPE) do Centro Universitário Senac. Participou da organização de diversos eventos científicos, tendo sido, entre outros, general chair do SVR 2004 (Symposium on Virtual and Augmented Reality), Program Chair do SVR 2007 e do SBGames 2005, General Vice-chair do SVR 2008 . Atualmente é Presisdente do Comitê Científico do P \& D Design 2008. Já orientou 4 teses de doutorado e 11 dissertações de mestrado, além de inúmeros trabalhos de iniciação científica, de conclusão de curso de graduação e de pós-graduaçào lato sensu. Atualmente orienta 4 alunos de doutorado, 5 de mestrado e dois alunos de iniciação científica (um PIBIC). Coordena, a partir de setembro de 2007, um projeto de pesquisa financiado pela FAPESP dentro do programa TIDIA-Ae (Aprendizagem Eletrônica na Internet Avançada). Os termos mais freqüentes na contextualização de sua produção científica, tecnológica e artístico-cultural são: Computação Gráfica, Design, Realidade Virtual, Multimídia, Hipermídia, Educação Virtual Interativa, Educação, Tecnologia Educacional, Educação a Distância e Computer games.

<tori@acm.org> 